\title{
MARIONETES E MAQUETES TÁTEIS: PERCEPÇÃO E APROPRIAÇÃO DO REPERTÓRIO ESPACIAL E CORPORAL COMO SUBSÍDIO AO DEFICIENTE VISUAL EM ATIVIDADES DE DANÇA
}

\author{
COELHO, Isabela da Silva (1); \\ BERNARDI, Núbia (2); \\ (1) Universidade Estadual de Campinas, Faculdade de Engenharia Civil, Arquitetura e \\ Urbanismo, Graduanda em Arquitetura e Urbanismo. \\ e-mail: belacoelhoc@gmail.com \\ (2) Universidade Estadual de Campinas, Faculdade de Engenharia Civil, Arquitetura e \\ Urbanismo, Professora Doutora \\ e-mail: nubiab@fec.unicamp.br
}

\begin{abstract}
RESUMO
Este artigo apresenta o resultado de uma pesquisa que propôs um estudo de caso sobre o aprendizado de movimentos do ballet para crianças com deficiência visual, utilizando-se instrumentos táteis. Para entender as principais dificuldades dos estudantes, houve 0 acompanhamento de uma turma infantil de ballet para deficientes visuais. Foi proposta uma dinâmica através da manipulação de marionetes e maquetes táteis possibilitando um entendimento do repertório espacial e corporal através do tato. Pode-se concluir que o auxílio destes instrumentos contribui para proporcionar às crianças estudantes de dança que são deficientes visuais um aprendizado lúdico e acessível capaz de incrementar sua consciência espaço-corporal.
\end{abstract}

Palavras chave: marionetes e maquetes táteis; acessibilidade; consciência espaço-corporal.

\begin{abstract}
This article presents the result of a research that proposed a case study on learning ballet movements for children with visually impaired using tactile instruments, these enable a better understanding of the spacial and body repertoire through the touch. To understand the main difficulties of the students, there was the monitoring of a children's ballet class for the visually impaired. There was proposed a dynamic through the manipulation of tactile puppets and tactile models enabling an understanding of spatial and bodily repertoire through touch. It can be concluded that the assistance of these instruments contributes to provide for the child dance students, who are visually impaired, a ludic and accessible learning capable to increase their body spacial awareness.
\end{abstract}

Keywords: tactile puppets and models; accessibility; body spacial awareness. 


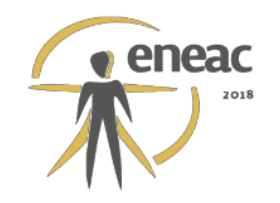

\section{INTRODUÇÃO}

Os padrões de desenvolvimento de uma criança cega seguem os mesmos de uma criança vidente, no entanto, deve-se compreender que este é um processo dinâmico de interação com o meio, no qual o amadurecimento das estruturas sensoriais e motoras ocorre através de contínua troca entre os estímulos e as respostas dos ambientes em que convivem. Desta forma, é necessário estimular as estruturas sensoriais desde muito cedo para compensar a deficiência visual e diminuir a defasagem psicomotora, que pode comprometer a evolução postural e o equilíbrio estático e dinâmico da criança.

Segundo Figueira (1996), é muito importante desenvolver um tato ativo nas crianças cegas, para que elas explorem o ambiente, seus contornos e formas, a fim de formar imagens que possam aumentar sua segurança e seu interesse pelo meio no qual se encontram. Com isso, há um maior conhecimento de detalhes, como distâncias e relações espaciais, o que facilita sua locomoção no espaço e sua integração com o meio. A mobilidade também é um fator importante, já que é a capacidade do indivíduo se locomover de acordo com estímulos, e o seu domínio pela criança ou jovem deficiente visual permite a oportunidade de se desenvolver e de explorar o que o cerca, para que ele possa interagir ativamente no ambiente.

Atualmente, tem-se conhecimento de que a dança é uma atividade que aprimora a coordenação, a noção espacial, a concentração, a segurança física/motora do corpo e a interação com outras pessoas, entre outros benefícios. Por conta desta importância, a dança deve incluir diversos perfis de praticantes, como as pessoas com deficiência. No caso do deficiente visual, o desenvolvimento do senso da competência motora é formado ao longo da vida da mesma forma que as pessoas videntes, e a dança contribui na percepção entre o corpo que se movimenta e o ambiente que o cerca. Desta forma, esta atividade deve ser incorporada não só a crianças, mas também à adultos, e principalmente aos deficientes visuais, já que ela trabalha aspectos que envolvem a construção do pensamento, da criatividade e também as ideias de tempo-espaço, melhorando a manutenção do equilíbrio e da postura corporal (CDOF - Cooperativa do Fitness, 2009 apud LONDERO, 2011).

"A identificação narcísica permite considerar que o sujeito percebe e apreende o espaço a partir de si mesmo. É, pois, graças a isso, ao fato de o espaço se tornar parte do sujeito que com eles se identifica que o ambiente construído se torna imprescindível, oferecendo uma possível explicação para o caráter insubstituível que determinados espaços edificados adquirem, mesmo quando funcionalmente poderiam ser perfeitamente substituíveis." (LEITÃO, 2002, p. 367)

Pensando-se no espaço para dança, a interação corpo/ambiente faz-se imprescindível, para não dizer indissociável. Conhecer e perceber o espaço para o desempenho de uma atividade corporal/artística é muito importante para o bailarino ou estudante de dança. Neste sentido, a utilização de maquetes táteis poderia potencializar a performance de deficientes visuais na dança, pois haveria o conhecimento do espaço de cena e de atuação, o que utiliza outras fontes de percepção, que não a visual, aumentando o campo de aprendizagem. "A limitação do indivíduo cego está relacionada à percepção visual; entretanto suas outras fontes de percepção estão intactas e possibilitam a aprendizagem." (CAZÉ, 2008; OLIVEIRA, 2008, vol. 11 n.3) 


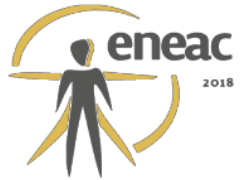

A interação e o conhecimento do ambiente são fundamentais para o exercício das atividades humanas. Indivíduos com deficiência visual percebem o espaço construído a partir de outros referenciais hápticos, potencializados pela audição, tato e olfato. Estes indivíduos necessitam de um suporte suplementar para compreender um ambiente em sua totalidade. Maquetes táteis e instrumentos manipuláveis podem auxiliar nesta compreensão do ambiente e seu entorno (COLL, 1995 apud BIANCHINI, 2005).

\section{OBJETIVOS}

A inserção de pessoas com deficiência na sociedade pode acontecer em diversos âmbitos, dessa forma são necessárias políticas de acessibilidade no âmbito da mobilidade urbana, da empregabilidade, da educação, dos direitos humanos, da cultura e do lazer. Segundo Sassaki (2004) a acessibilidade pode ser classificada em sete segmentos: arquitetônica, comunicacional, metodológica, instrumental, programática, atitudinal e de discriminação. Esta pesquisa insere-se na categoria da acessibilidade instrumental que, segundo o autor, pretende eliminar barreiras nos instrumentos e ferramentas de ensino, trabalho e lazer. Especificamente, o objetivo principal foi observar a efetividade da utilização de maquetes e marionetes táteis na aprendizagem de atividades que incorporam o espaço de atuação da dança e do teatro, para deficientes visuais. Pretendeu-se, com tal dinâmica, auxiliar estes indivíduos em atividades de repertório espacial e corporal, como subsídio para sua consciência espaço-temporal.

\section{METODOLOGIA}

Inicialmente, a fim de melhorar o embasamento teórico, houve uma revisão da bibliografia, que incluiu estudos a respeito do aprendizado de pessoas com deficiência visual, a importância do ballet e da dança no desenvolvimento da criança, o estudo do Método Fernanda Bianchini, a importância educacional das marionetes no desenvolvimento infantil e, também, a importância das maquetes táteis no conhecimento do ambiente por não videntes.

Após esta etapa, utilizou-se como metodologia a técnica da área da Psicologia Ambiental e Comportamental, visto sua interface indivíduo/ambiente (RHEINGANTZ, 2009), a fim de aferir as informações da turma estudada e elaborar a maquete e as marionetes táteis. Dois métodos conjugados e adaptados foram utilizados:

1. Mapa comportamental: originário da Psicologia Ambiental, concebido como registro gráfico das observações relacionadas às atividades dos usuários (fluxos, interações, movimentos, apropriação do espaço) em determinado ambiente. Neste projeto as observações estão relacionadas aos movimentos do corpo determinados através das técnicas de consciência corporal.

2. Mapa mental ou mapeamento cognitivo: consiste na elaboração de desenhos ou relatos de memória representando ideias ou imaginabilidade no uso de um determinado ambiente, incorporando experiências pessoais. Neste projeto o mapeamento cognitivo aconteceu através da manipulação de elementos tridimensionais (maquetes e marionetes táteis) que simulam os movimentos do corpo e a percepção do ambiente de entorno. 


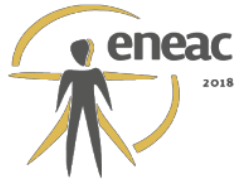

\section{MÉTODO FERNANDA BIANCHINI}

Fernanda Bianchini é uma fisioterapeuta e bailarina formada que desenvolveu um método para o ensino do ballet para cegos, e que é utilizado no Brasil e no mundo. Segundo Bianchini (2005), para que uma pessoa aprenda a dançar é necessário que copie os movimentos realizados pelo professor, através da visualização da imagem deste refletida em um espelho. Outro pressuposto para o aprendizado da dança é conseguir localizar o próprio corpo no espaço, seja na sala de aula ou no palco.

"É através do olhar que mostro a necessidade da relação com o espaço. O espaço é limitante e é necessário conviver com ele, aprender a olhar os limites da sala e além da sala. (...) Cada um começa a descobrir o próprio corpo, seu ritmo, e somente aí esse corpo pode começar a dançar, interpretar, se expressar". (VIANNA, 1990, p. 127 apud BIANCHINI, 2005 p. 34).

Seguindo este pensamento, teoricamente uma pessoa com deficiência visual não poderia aprender a dançar, porém a partir do método de Fernanda, com a percepção através do tato e da audição, a dança pode ser ensinada e incorporada por alunos cegos. O método foi desenvolvido com base nos movimentos que o deficiente aprendeu e adquiriu ao longo da vida, sendo que cada passo é ensinado através de brincadeiras e histórias. Para que os alunos possam aprender é necessário que eles tenham consciência e confiança corporal e espacial, a fim de experimentar os movimentos e as possibilidades que o ballet permite.

O ensino dos passos do ballet no Método Bianchini é feito pela audição e pelo tato, sendo que no primeiro, a professora descreve os passos a partir de movimentos já conhecidos pelos alunos, como aqueles aprendidos no dia a dia. Já no tato, o aluno toca o corpo da professora a fim de entender como é feito o passo, e a professora também tateia o corpo do aluno para possíveis correções. Este é feito no ar e no chão, para permitir maior estabilidade e entendimento.

\section{INSTRUMENTOS AUXILIARES NA EDUCAÇÃO}

\subsection{As Marionetes}

"O universo encantado do teatro de bonecos, que envolve públicos de todas as idades e classes sociais, não proporciona apenas diversão e entretenimento, mas pode ser utilizado como instrumento para fins educativos de qualquer natureza." (SILVA, 2011, p. 11).

Atualmente, o teatro de marionetes vem sendo usado como uma forma lúdica de aprendizagem, possuindo assim, além do caráter artístico, um caráter pedagógico, também, ampliando as possibilidades de lecionar dos professores e de aprender das crianças. Piaget (1997) apud GUERRA; GUSMÃO; SIBRIÃO (2004) dizia que as práticas lúdicas com as crianças são válidas, pois além de serem uma forma de lazer, elas desenvolvem os estudantes intelectualmente.

Percebe-se que o ensino da arte colabora tanto para a construção intelectual, quanto para a moral e a social, capacitando o indivíduo de reconhecer a si mesmo e o grupo ao qual pertence. $\mathrm{O}$ ato de brincar, jogar e se movimentar, por exemplo, permite que a criança se aproprie do repertório da cultura corporal, colaborando para o seu desenvolvimento motor e a segurança dela em relação ao meio em que se encontra. Este processo é muito importante, pois é na infância que ocorre a construção do ser autônomo, a partir da identificação de seus gestos, preferências, habilidades e limites (FRAZÃO, 2014). 


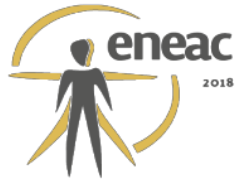

\subsection{As Maquetes Táteis e Não Táteis}

"[...] a maquete é de grande importância na comunicação de ideias no processo projetual. Ela expressa mais diretamente a intenção de projeto, principalmente para o cliente e usuários com pouca experiência na leitura de desenhos." (KOWALTOWSKI ,2006, p. 15).

As maquetes são um recurso frequentemente utilizado na arquitetura para facilitar 0 entendimento de ambientes e construções, permitindo esclarecer o projeto e seus desdobramentos. Porém, por ser um elemento muitas vezes visual, não inclui usuários com baixa ou perda total da visão, por exemplo, o que não o torna completamente inclusivo. Para deficientes visuais, a principal forma de reconhecimento espacial é a experiência direta com o ambiente, a partir da compreensão das principais informações nele obtidas e que podem facilitar a movimentação, entretanto muitas vezes este método não é possível devido a inúmeros fatores, o que prejudica e limita sua locomoção (MILAN, 2008).

Com isso, a partir da adaptação das maquetes, tornando-as elementos táteis, permite que o reconhecimento espacial seja mais rápido e eficiente, por meio da representação fiel e proporcional de ambientes e construções, utilizando materiais com características táteis semelhantes àquelas do ambiente real, e tornando a arquitetura mais inclusiva. Como a maquete tátil é de extrema importância para a inclusão destes usuários, o estudo da durabilidade, da escala e dos materiais que serão utilizados para representar os reais deve ser realizado cuidadosamente, para que a eficiência da maquete tátil alcance os objetivos esperados.

\section{DESENVOLVIMENTO DA DINÂMICA}

Com a finalidade de entender melhor as necessidades dos alunos de 4 a 8 anos de ballet para cegos da Associação Fernanda Bianchini, uma turma com a idade correspondente foi acompanhada. Com isso, foram realizadas 4 visitas para assistir as aulas e realizar as anotações necessárias, que consistiram em mapas comportamentais simplificados e tabelas nas quais são especificadas as atividades realizadas em cada dia e a quantidade de alunos presentes. A Tabela 1 mostra os dias de visitas de acompanhamento das atividades da turma em sala de aula. A turma em questão é formada por diversos alunos, sendo que a maior quantidade de crianças presentes foi de 13, número que inclui crianças com deficiência visual, baixa visão e deficiências motoras. Existem várias professoras, devido a necessidade de acompanhar cada aluno individualmente durante os exercícios, sendo que a responsável pela turma é uma bailarina formada pela CIA Ballet de Cegos e que possui deficiência visual de causa adquirida.

Tabela 1 - Data, quantidade de alunos e exercícios realizados.

\begin{tabular}{|c|c|c|}
\hline DATA & ALUNOS & EXERCÍCIOS \\
\hline $24 / \mathrm{fev}$ & 10 & $\begin{array}{l}\text { Exercícios de alongamento e fortalecimento, aprendizagem de } \\
\text { alguns passos de ballet. }\end{array}$ \\
\hline $10 /$ mar & 13 & $\begin{array}{l}\text { Exercíciosdealongamentosem rodae alunosfazem passé } \\
\text { deitados e depois em pé; aprendem a contagem do ballet por } \\
\text { meio de palmas. }\end{array}$ \\
\hline $31 /$ mar & 12 & Exercícios de alongamento e de reconhecimento espacial. \\
\hline 19/mai & 3 & $\begin{array}{c}\text { Exercícios de alongamento e fortalecimento mais voltados para a } \\
\text { fisioterapia. }\end{array}$ \\
\hline
\end{tabular}




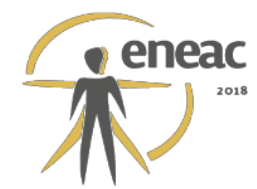

Fonte: elaborado pelos autores.

O estudo realizado foi baseado na psicologia ambiental e nos objetivos das pesquisas realizadas nesta disciplina de acordo com Esther Wiesenfeld (2005). A Figura 1 mostra as etapas adaptadas da pesquisa de Wiesenfeld e a Figura 2 os diagramas de permanência dos alunos na sala de aula. As manchas em vermelho representam os locais de permanência e atividades práticas das aulas.

Figura 1 - Sequência da pesquisa baseada no trabalho de Wiesenfeld (2005).

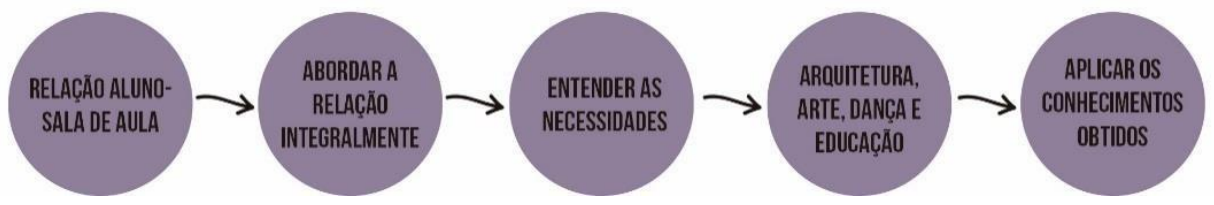

Fonte: elaborado pelos autores.

Figura 2 - Diagrama de permanência da sala de aula.
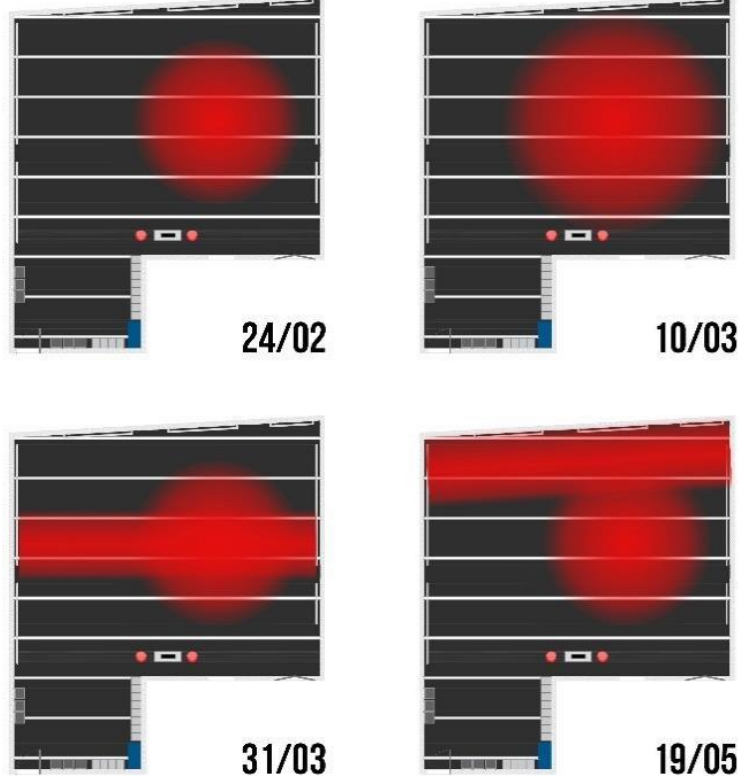

Fonte: elaborado pelos autores.

A partir dos dados obtidos pela análise da relação do aluno com deficiência visual com o local de aprendizado, percebeu-se que a sala de aula em questão é pouco aproveitada quando o seu espaço útil é considerado, sendo que o canto direito é utilizado a maior parte do tempo nas quatro aulas acompanhadas. Este fator pode estar relacionado a possível falta de segurança e de conhecimento do ambiente no qual a criança se encontra, o que dificulta a sua utilização. Além disso, os alunos com deficiência visual possuem uma grande dificuldade de interpretar passos do ballet que envolvem movimentos compostos, como os saltos e as piruetas.

Para compreender melhor a perspectiva do ponto de vista da docente, foi aplicado um questionário para a Professora, após a explicação e apresentação do projeto. 


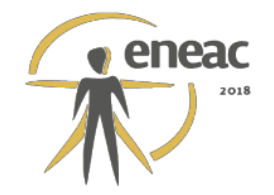

Questionário para a professora (em itálico encontram-se as respostas da mesma)

1. Já utilizou uma maquete tátil? Como foi a experiência? Sim, foi como tatear uma pequena cidade.

2. Qual dificuldade é maior por parte dos alunos em relação a sala de aula, principalmente das crianças com deficiência visual? Acho que entender e interpretar os passos que envolvam saltos, piruetas, já que são mais abstratos.

3. Quais passos seriam mais interessantes de serem trabalhados numa marionete tátil? E quais elementos seriam mais importantes de serem representados? Saltos mais básicos, já que são crianças. Deve ser mais parecido com bonecas né, para as crianças sentirem vontade de usar.

Com as respostas geradas pelo questionário, pode-se perceber que o que foi observado pela pesquisadora durante as aulas se assemelha as impressões da professora. Com isso, o estudo para o desenvolvimento da maquete tátil e da marionete tátil pode ter início, considerando os principais obstáculos enfrentados pelos alunos e as possíveis melhorias que estes objetos poderiam proporcionar, utilizando os conceitos estudados na arquitetura, na psicologia ambiental, na dança e na educação.

\subsection{Confecção da Maquete Tátil}

Foi confeccionada uma maquete tátil da sala de aula. A escala da maquete foi escolhida considerando a idade dos alunos e os usuários desta, sendo que a maior medida da maquete deveria ter a abertura do braço de uma criança da faixa etária estudada. Também foi considerada a necessidade de torná-la mais lúdica, e consequentemente mais atrativa para os alunos. Com isso, os materiais escolhidos se assemelham mais ao repertório cotidiano da criança, melhorando a sua interpretação. A maquete foi produzida pelo software AutoCAD, que possibilitou o desenvolvimento da planta baixa com as medidas obtidas a partir das visitas realizadas à instituição (Tabela 2 e Figuras 3 e 4).

Tabela 2 - Descrição do material real e do material simulado utilizado na maquete e suas características táteis.

\begin{tabular}{|c|c|c|}
\hline MATERIAL REAL & MATERIAL SIMULADO & CARCATERÍSTICAS TÁTEIS \\
\hline Espelho & Acetato com papel chumbo & Liso, sensação de frio, reflexivo. \\
\hline Parede & Papel panamá pintado & $\begin{array}{c}\text { Áspero, pouco granulado, duro, rígido e } \\
\text { maciço. }\end{array}$ \\
\hline Piso de linóleo & EVA & Emborrachado, liso, confortável. \\
\hline Faixas do piso & Fita durex cortada & Liso, escorregadio, sensação de frio. \\
\hline Cadeiras plásticas & Placa da PVC pintada & Levemente áspero, sensação de frio, dureza. \\
\hline Armários metálicos & Acetato & Liso, sensação de frio, rígido, derrapante. \\
\hline Barras metálicas & Papel chumbo & Liso, sensação de frio, rígido, derrapante. \\
\hline
\end{tabular}

Fonte: elaborado pelos autores. 


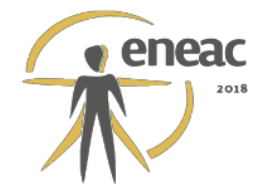

Figura 3 - Diagrama de localização dos materiais da maquete tátil.

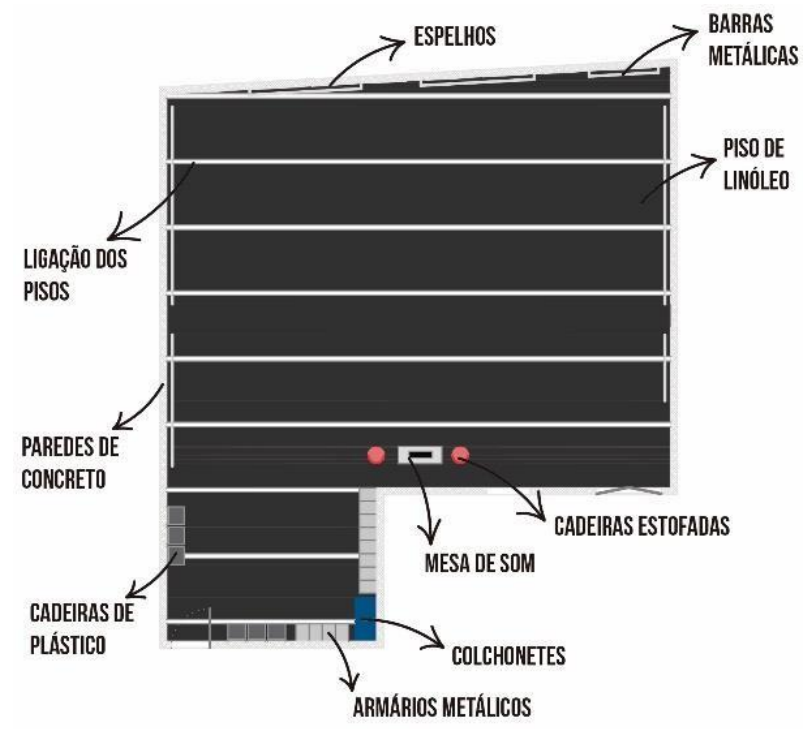

Fonte: elaborado pelos autores.

Figura 4 - Imagens da maquete tátil vista de cima.

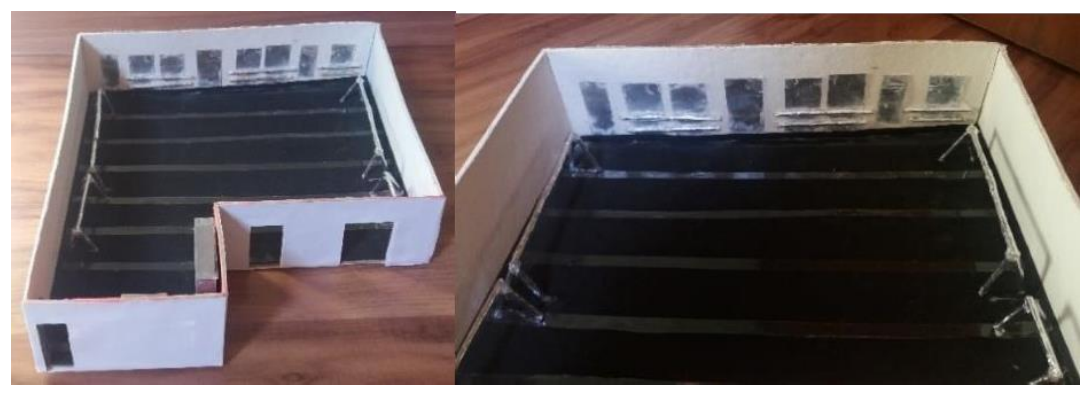

Fonte: elaborado pelos autores.

\subsection{Confecção das Marionetes Táteis}

Foram confeccionadas duas marionetes táteis. A escala destas também foi escolhida considerando o tamanho da mão e a amplitude do braço dos alunos, assim a interpretação da marionete como um todo não seria prejudicada. Além disso, por conta da escassez de materiais em relação às marionetes táteis, algumas características presentes nas marionetes dos teatros de bonecos foram adaptadas. As marionetes foram representadas com a ergonomia de uma criança e utilizando o vestuário característico do ballet. Além disso, para torná-las mais parecidas com as crianças, os olhos das marionetes foram feitos de corações, assim como foi proposto por Fernanda durante a apresentação do projeto em outubro de 2016. Assim como as maquetes táteis, a escolha dos materiais para a marionete tátil também é de extrema importância, a fim de torná-la mais lúdica e atrativa para a criança, cumprindo assim o seu papel como marionete na arte e na educação e como um elemento de inclusão na dança. A Tabela 3 especifica os materiais adotados para a confecção das marionetes, a Figura 5 mostra os movimentos simulados e a Figura 6 mostra as marionetes confeccionadas. 


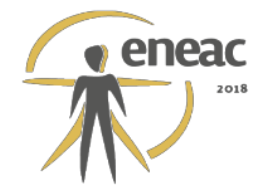

Tabela 3. Descrição do material real e do material simulado utilizado na marionete e suas características táteis.

\begin{tabular}{|c|c|c|}
\hline MATERIAL REAL & MATERIAL SIMULADO & CARCATERISTICAS TÁTEIS \\
\hline Pele & Biscuit & Liso, macio, temperatura ambiente. \\
\hline Cabelo & Cabelo sintético & Fios finos, gelados, rígidos. \\
\hline Collant & Tecido poliamida & $\begin{array}{c}\text { Tecido gelado, áspero, escorregadio, } \\
\text { elástico. }\end{array}$ \\
\hline Saia & Tule & Liso, gelado, rígido, sem elasticidade. \\
\hline Sapatilha & Tecido com lona & Macio, confortável. \\
\hline
\end{tabular}

Fonte: elaborado pelos autores.

Figura 5 - Croqui dos passos pirouette (a) e changement (b).

(a)

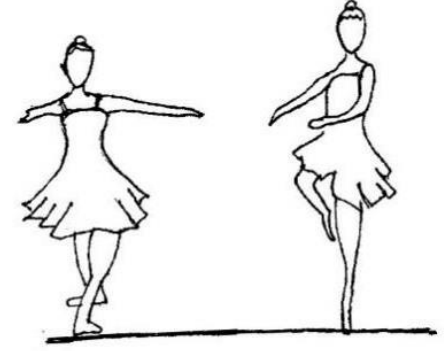

Fonte: elaborado pelos autores.

Figura 6. Imagens das marionetes táteis confeccionadas.

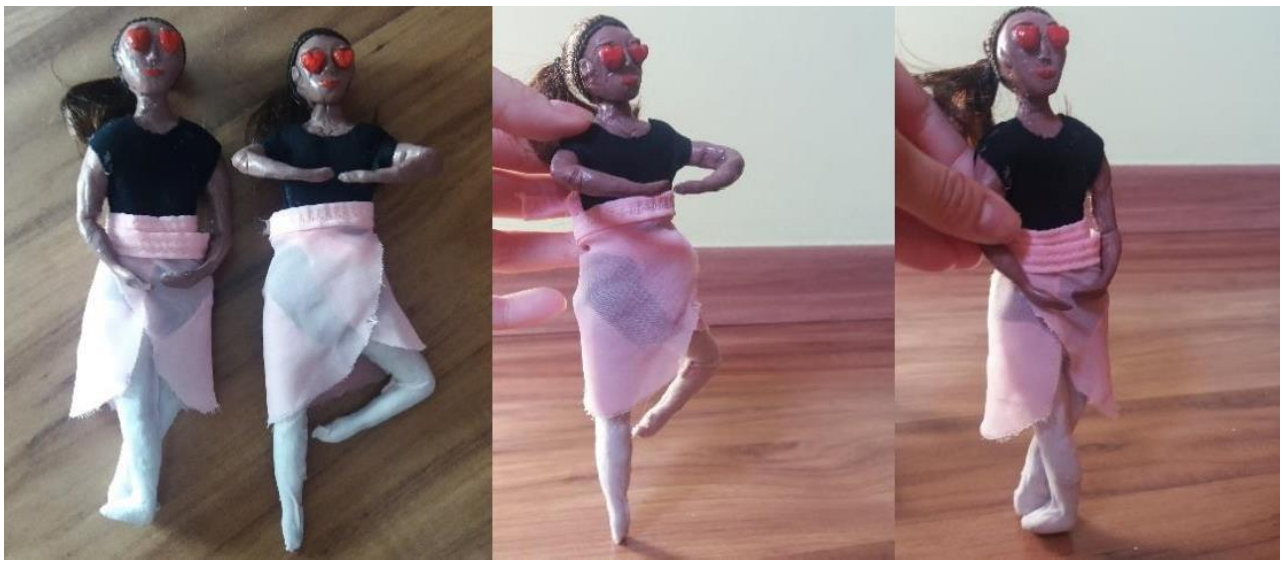

Fonte: elaborado pelos autores.

\subsection{Aplicação}

Para perceber a efetividade da utilização das marionetes e maquetes táteis, foi realizada uma dinâmica com as crianças, na qual elas tatearam as mesmas com o auxílio de suas professoras, com a devida autorização do Comitê de Ética em Pesquisa e dos respectivos 


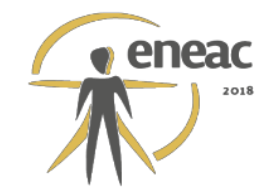

responsáveis, com a assinatura do Termo de Consentimento Livre e Esclarecido (TCLE) ${ }^{1}$. A dinâmica foi realizada no dia 11 de agosto de 2017 em São Paulo, na Cia Ballet de Cegos. No dia da dinâmica a turma era composta por 12 alunos sendo que três destes eram as crianças voluntárias com deficiência visual de idade entre 4 e 8 anos.

Antes do início da aula, a professora pediu para tatear as marionetes a fim de sentir e identificar os passos que estas representavam. Encantada com a ideia, e após realizar os alongamentos e a abertura, permitiu que as crianças tateassem as duas marionetes, evidenciando suas características, como o collant, a saia e a meia, todos de tecidos correspondentes aos quais elas usavam, e os corações no lugar dos olhos, que segundo uma das professoras mostrava que elas enxergavam com os olhos do coração, assim como os três alunos. Após tatearem as marionetes, a professora perguntava o que estava representado, e elas entenderam que era "lambendo o sorvete", uma expressão dada pela instituição e que representa o passé, parte da pirueta.

A dinâmica com a maquete foi mais restrita, já que as marionetes se mostraram mais atrativas para as crianças. Um fator que dificultou a percepção da maquete é que a instituição passou por reformas no período de julho e a sala de aula que foi estudada sofreu alterações tornando-a um pouco diferente daquela que a maquete representava, já feita anteriormente.

Figura 7. Imagens das mãos das crianças tateando as marionetes táteis.

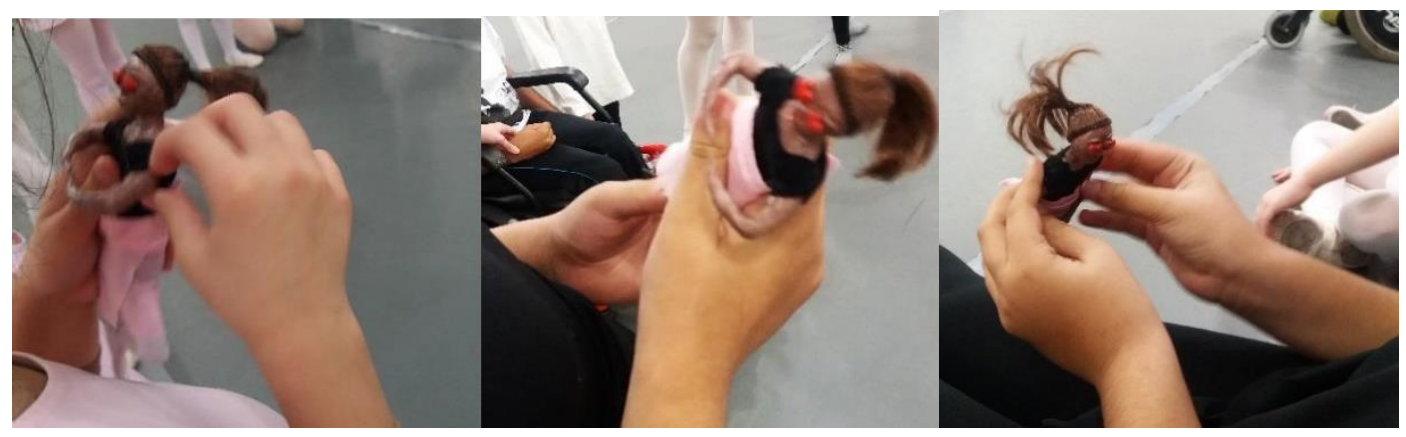

Fonte: elaborado pelos autores.

\subsection{Resultados}

Durante a dinâmica as professoras ficavam constantemente perguntando às crianças o que elas estavam sentindo e o que acharam das pequenas marionetes bailarinas. Os três alunos que participaram da dinâmica responderam positivamente, mostrando grande interesse pelas marionetes, sendo que uma das crianças após tatear a marionete e o questionarem sobre o que ela representava, levantou-se e realizou o passé com ambas as pernas, motivado pela representatividade desta. As professoras ficaram encantadas com a marionete, e uma das professoras se emocionou ao tateá-las.

\section{CONCLUSÕES}

A partir do acompanhamento da turma selecionada na Associação Fernanda Bianchini durante quatro sextas-feiras, foi possível conhecer as crianças com as quais a dinâmica seria realizada e suas maiores dificuldades. Com este acompanhamento e com os estudos

\footnotetext{
${ }^{1}$ A pesquisa foi aprovada pelo Comitê de Ética em Pesquisa e possui o número CAAE 65607217.2.0000.5404
} 


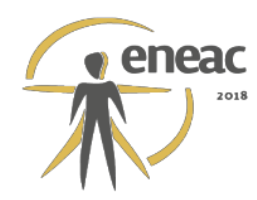

desenvolvidos e apoiados na revisão da bibliografia, formou-se um embasamento que permitiu o desenvolvimento das marionetes e maquetes táteis, estas que correspondiam às necessidades da turma trabalhada.

Com a realização da dinâmica, pode-se concluir que o auxílio que estes materiais podem proporcionar às crianças estudantes de dança e deficientes visuais é enorme e deve ser estudado com maior profundidade. Percebeu-se a importância da continuidade do projeto, já que este poderia incorporar outros aspectos pedagógicos da dança, transformando o ensino de dança para estudantes com deficiência visual um pouco mais lúdico através das marionetes e maquetes táteis, estas que são de baixo custo e acessíveis para todos. Além disso, seria interessante produzir uma marionete que tivesse articulações, a fim de permitir a realização de inúmeros outros passos e movimentos do ballet, tornando-a mais prática e inclusiva. Pode-se pensar em uma continuidade do projeto dedicando um número maior de dinâmicas pedagógicas assim como ampliar o cronograma de pesquisa com a finalidade de incorporar o acompanhamento e a evolução dos alunos após a utilização e manipulação das maquetes e marionetes táteis.

\section{AGRADECIMENTOS}

Este projeto foi financiado pelo PIBIC - CNPq, sendo o seu apoio imprescindível. Também é importante salientar o agradecimento à Associação Fernanda Bianchini, por estar sempre aberta a conversas e projetos e a todas as professoras que participaram por serem receptivas e prestativas, além de os responsáveis dos voluntários e os mesmos, por se tornarem parte da pesquisa e aceitarem participar da mesma.

\section{REFERÊNCIAS BIBLIOGRÁFICAS}

BIANCHINI, Fernanda C. Ballet Clássico para Deficientes Visuais: Método Fernanda Bianchini. Dissertação de Mestrado. São Paulo: Universidade Presbiteriana Mackenzie, 2005.

CAZÉ, Clotildes Maria de Jesus Oliveira; OLIVEIRA, Adriana da Silva. Dança além da visão: possibilidades do corpo cego. Revista Pensar a Prática. Volume 11, número 3, 2008.

CDOF, Cooperativa do Fitness. A dança aplicada na escola. 2009. Disponível em: <http://www.cdof.com.br/danca5.htm> In: LONDERO, Rosana M.A. A Dança na Escola e a Coordenação Motora. 47f. Fortaleza: Monografia, Licenciatura em Artes, Faculdade Integrada da Grande Fortaleza - FGF, 2011.

COLL, César; PALACIOS, Jesus; MARCHESI, Álvaro. Desenvolvimento Psicológico e Educação: Necessidade Educativas Especiais e Aprendizagem Escolar. Vol 3, Porto Alegre, Artes Médicas, 1995. In: BIANCHINI, Fernanda C. Ballet Clássico para Deficientes Visuais: Método Fernanda Bianchini. Dissertação de Mestrado. São Paulo: Universidade Presbiteriana Mackenzie, 2005.

FIGUEIRA, Maria M.A. Assistência fisioterápica à criança portadora de cegueira congênita. Revista Benjamin Constant, Centro de Pesquisa, Documentação e Informação, Rio de Janeiro, n. 5, dez. 1996.

FRAZÃO, Ironilde G. Inventividade com Teatro de Bonecos. Revista Diálogos Interdisciplinares GEPFIP, Aquidauana, v.1, n.1, p.106-113, 2014.

GUERRA, R.A.T.; GUSMÃO, C.R.C.; SIBRIÃO, E.R. Teatro de Fantoches: Uma Estratégia em 


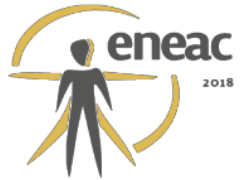

Educação Ambiental. In: Global Trends on Environmental Education. AZEITEIRO, U. M., PEREIRA, M. J., LEAL-FILHO, W., CAEIRO, S., BACELAR-NICOLAU, P., MORGADO, F. and GONÇALVES, F. (Eds), Discursos, Universidade Aberta, Lisboa, no especial: 361-375. 2004.

KOWALTOWSKI, D. C. C. K.; CELANI, M. G. C.; MOREIRA, D. C.; PINA, S. A. M. G.; RUSCHEL, R. C.; SILVA, V. G. da; LABAKI, L. C. ; PETRECHE, J. R. D. Reflexão sobre metodologias de projeto arquitetônico. In: Ambiente Construído, Porto Alegre, 2006, v. 6, n.2 . pp 14-15

LEITÃO, L. Espaço do Abrigo? Espaço do Afeto! In: RIO, V. DEL, DUARTE, C.R. RHEINGANTZ, P. A (Eds). Projeto do lugar: colaboração entre psicologia, arquitetura e urbanismo. Coleção PROARQ, Rio de Janeiro: Contra Capa, 2002. P. 365-369

LONDERO, Rosana M.A. A Dança na Escola e a Coordenação Motora., 47f. Fortaleza: Monografia, Licenciatura em Artes, Faculdade Integrada da Grande Fortaleza - FGF, 2011.

MILAN, Luis F. Maquetes Táteis: Infográficos Tridimensionais para a Orientação Espacial de Deficientes Visuais. Revista PARC - Pesquisa em Arquitetura e Construção, FEC Unicamp, Vol.1 №2, 2008.

PIAGET, J. 1997. Seis estudos de Psicologia. Rorense, Rio de Janeiro apud GUERRA, R.A.T.; GUSMÃO, C.R.C.; SIBRIÃO, E.R. Teatro de Fantoches: Uma Estratégia em Educação Ambiental. In: Global Trends on Environmental Education. AZEITEIRO, U. M., PEREIRA, M. J., LEAL-FILHO, W., CAEIRO, S., BACELAR-NICOLAU, P., MORGADO, F. and GONÇALVES, F. (Eds), Discursos, Universidade Aberta, Lisboa, ํo especial: 361-375. 2004.

REINGHANTZ, P.A.; AZEVEDO, G.A.; BRASILEIRO, A; ALCÂNTARA, D.D.; QUEIROZ, M. Observando a qualidade do lugar: procedimentos para a avaliação pós-ocupação. ProArq. Edição eletrônica. Rio de Janeiro: Universidade Federal do Rio de Janeiro, Faculdade de Arquitetura e Urbanismo, Pós-Graduação em Arquitetura. Disponível em <www.fau.ufrj.br/prolugar,2009> acesso em 12 de abril de 2017.

SASSAKI, R. Revista do Terceiro Setor, 04 de junho de 2004. Disponível em $<$ http://arruda.rits.org.br> Acesso em janeiro de 2017.

SILVA, Maria N. M. Teatro de Fantoches: Uma Atividade Cênica como Estratégia para Aprendizagem no Ensino Infantil. Cruzeiro do Sul: Departamento de Artes Cênicas da Universidade de Brasília, 2011.

VIANNA, 1990, K. A Dança. São Paulo, Siciliano. In: BIANCHINI, Fernanda C. Ballet Clássico para Deficientes Visuais: Método Fernanda Bianchini. Dissertação de Mestrado. São Paulo: Universidade Presbiteriana Mackenzie, 2005.

WIESENFELD, Esther. A Psicologia Ambiental e as Diversas Realidades Humanas. Instituto de Psicologia, Universidade Central da Venezuela. In: Psicologia USP, 53-69, 2005. 